\section{Bacterial species - from theory to practice}

Marek Bartoszewicz

DOI: $10.24131 / 3247.180101$

Summary:

Although the Mayr's definition of species is commonly accepted for eukaryotic organisms, bacteria do not meet those established criteria. Thus, a special approach is necessary to elaborate the definition resistant to such limitations as for example the lack of sexual reproduction or horizontal gene transfers. One of the most problematic taxa in microbiology is the Bacillus cereus group composed of several closely related bacteria. Thus, on the basis of this model, doubts concerning bacterial taxonomy are discussed in the light of actual, molecular data.

Key words: taxonomy, phylogeny, species, bacteria

\section{received: 29.05 2017: accepted: 30.06.2017: published: 13.12,2017}

Marek Bartoszewicz, Ph.D.: Department of Microbiology, Institute of Biology, Faculty of Biology and Chemistry, University of Bialystok

\section{Introduction}

The definition of biological species includes the basic unit of biological classification and also a rank defined by Ernst Mayr as a group of individuals that can produce fertile offspring, usually by sexual reproduction and are reproductively isolated from other populations (Mayr, 1942). Next, members of the same species occupy similar environmental niches and have the same phylogenetic origin (Mayr, 1982). While this concept is accepted, it may be problematic in case of numerous organisms. Problems may be linked to interspecific hybridization, presence of chromosomal races like among common shrews (Fedyk and Chetnicki, 2007; Ratkiewicz et al., 2002) or ring species observed among birds. Next exceptions can be seen when organisms reproduce asexually (by mitosis) or when parthenogenesis occurs. Moreover, in paleontology it is rather impossible to verify sexual reproduction of extinct life-forms.

Unfortunately, this definition is also inappropriate in bacteriology. Bacterial diversity is much higher than observed among other organisms, probably due to common occurrence in soil, air, water and food, their fast multiplication (time of generation under optimal conditions often does not exceed 30 minutes) and weak correctional activities of their polymerases (Cohan, 2002a; 2002b). Moreover, haploid genome and intensive horizontal gene transfer complicate their diversity even more. Next, still bacterial diversity is only particularly explored and only a small part of bacterial species has been already described (Cohan and Perry, 2007). In some circumstances, specific requirements (e.g. nutrients, media composition, and pressure) lead to problems with cultivation of bacteria. However pure bacterial culture is necessary in order to describe a new species (Małek et al., 2005). The scope of this paper is to describe the actual knowledge focused on the concept of bacterial species and to discuss important problems with cohesive taxonomy concept of microbes by the aid of interesting examples.

\section{From history to the present days}

Bacteria were initially discovered by Antonie van Leeuwenhoek (1632-1723) in late seventeenth century, but the role of these microscopic forms remained un- known. Finally, Louis Pasteur demonstrated microbiological fermentation and suggested that microbes may cause diseases of mammals, including humans. However, the milestone in bacterial taxonomy was reached by Robert Koch and his procedure for isolation of pure bacterial cultures using solid media for bacterial growth. Using recent findings, a basic and artificial taxonomy focused especially morphology of cells and colonies, as well as bacterial properties and virulence was constructed. Next, biochemical activity gained importance, usually followed by numerical analyses. Nevertheless, the discovery of molecular methods and elaboration of several DNA-based techniques has allowed for a real progress in bacterial taxonomy (Maughan and van der Auwera, 2011). In this approach, total DNA-DNA hybridization level (depicting an overall similarity between compared genomes) and $\mathrm{G}+\mathrm{C}$ content (measuring a proportion of guanine and cytosine nucleotides in total DNA) were assessed (Małek et al., 2005). However, these techniques have also several limitations. For example, similar values of $\mathrm{G}+\mathrm{C}$ content are often observed for distinct taxa, while DNA-DNA hybridization is expensive and time-consuming, tricky method. Nowadays, nucleotide sequencing techniques including analysis of ribosomal RNA organized in $r r n$ operon (Fig. 1) or sequencing of so-called housekeeping genes (multi-locus sequence typing) enable the development of natural system reflecting the phylogeny and evolutionary traits of bacteria domain (Rasko et al., 2005; Raymond et al., 2010). Unfortunately, even rRNA analyzes are not the perfect solution. Its relatively conservative characteristics prevents from the detection of subtle differences between closely related species, which may exhibit identical sequences of the 16S rRNA gene (Bartoszewicz et al., 2009). Thus, the concept of bacterial species is still widely discussed and requires further investigations to develop universal genetic markers and 
optimal, commonly accepted phenotypic features. At present, hopes are associated with techniques based on the whole-genome analyzes (Liu et al., 2015). Digital DNA-DNA hybridization provides more accurate data than its spectrophotometric variant, while using of the whole-genome sequence-based Genome BLAST Distance Phylogeny (GBDP) approach leads to the description of new taxa among groups of already known strains (Meier-Kolthoff et al., 2013).

\section{What do we call ‘bacterial species'?}

The definition of biological species was developed for organisms with sexual reproduction and it works well in the case of numerous plants or animals. According to its assumptions, sexual isolation leads to the speciation process because of the lack of the gene flow between distinct populations. Unfortunately, these guidelines proposed by Ernst Mayr, cannot be directly applied to the microorganisms. Thus, new problems arise. First of all, there must be a discreet force that binds bacteria belonging to one species and supports their differentiation from other bacteria. We can hypothesize that natural selection plays that role. According to the basics of theory of evolution, it favors adaptive mutations increasing microbial fitness and eliminates less adapted bacteria. Apart from a directional, stabilizing and disruptive selection, often described for eukaryotic organisms, bacteria are also affected by similar environmental pressure. Among others it turns out that purifying selection, leading to the clonal structure of microbial populations was described. Extreme cases of antibiotic resistance, like Klebsiella pneumonia New Delhi (Khan et al., 2017) or narrow specialization of pathogens, like B. anthracis, an anthrax agent (Kolsto et al., 2009) may have huge role in adaptation to host or 'hospital environment'. Finally, different species should evolve independently, however it is not clear whether their evolution is mostly supported by their horizontal gene transfer or environmental pressure (Wiedenbeck and Cohan, 2011).

Although there is no agreement as to the coherent definition of bacterial species, the most widely accepted definition assumes that one species includes a group of closely related bacteria, with common ancestor, having

\section{Genes}

\begin{tabular}{cll} 
16S rRNA $\quad$ 23S rRNA & 5S rRNA tRNA \\
\hline
\end{tabular}

Small sub-unit

Large sub-unit of ribosome

\section{Fig. 1. Organization of ribosomal RNA operon ( $r r n$ ) in prokaryotes}

Nucleotide sequence of $16 \mathrm{~S}$ rRNA (corresponding to ribosomal small subunit) is composed of numerous hypervariant regions (suitable for the assessment of phylogenetic relationships of closely related bacteria) and conservative regions (optimal for investigations of bacteria pertaining into one genus or family). $23 \mathrm{~S}$ and $5 \mathrm{~S}$ rRNA necessary for a large sub-unit are also objects of molecular genotyping.

at least $97 \%$ identity of the $16 \mathrm{~S}$ rRNA gene sequence and not less than $70 \%$ similarity of DNA-DNA hybridization. Moreover isolates from one species must be distinguishable from other species on the basis of one or more phenotypic properties (Małek et al., 2005), e.g. motility, toxicity or adaptation to grow at cold (psychrotolerance).

\section{Universal taxonomy \\ - 'Holly Graal' for microbiologists}

The microspace of bacteria is extremely differentiated and distinct apart from the world of eukaryotes, however both of them interpenetrate each other. Nevertheless, a question arises if the definition of bacterial species fits to all microorganisms and if not, what are the doubts and problems for further consideration. This can be well illustrated by the use of a suitable and complex microbiological model. Here an example of Bacillus cereus sensu lato group of bacteria appears useful, as its taxonomy is being discussed for several years (Jensen et al., 2003). This group is composed of several closely related species, but mainly of $B$. cereus (food poisoning causative factor), B. thuringiensis (used for production of biopesticides) and B. anthracis, an anthrax causative factor (Bartoszewicz et al., 2006; Moayeri et al., 2015). Not all of these bacilli can be morphologically distinguished from each other, e.g. under microscopy. However, according to the definition of bacterial species, there must be some features enabling their identification. Thus B. anthracis differs by forming characteristic poly-D-glutamic capsule that prevents this organism from phagocytosis by the neutrophils or macrophages of the host (Mock and Fouet, 2001). Next, it forms two different toxins, a lethal toxin and edema factor, both involved in the development of anthrax symptoms. What is more, B. anthracis is non-motile and suscep- 
tible to penicillin, an antibiotic produced by Penicillum sp. In turn, B. thuringiensis does not show any virulence to vertebrates. However, during sporulation (a process of forming dormant spores, structures highly resistant to environmental stresses), this bacterium produces crystalline inclusions composed of delta-proteins, often called Cry toxins (Święcicka, 2008). Crystals can be visualized by a specific staining or by the use of phasecontrast microscopy. Next example is B. cereus, which is involved in emetic and diarrheal syndromes and occasional infections. It is also devoid of parasporal inclusions and it is believed to be incapable to synthesize anthrax toxins, however it forms its own toxic peptides active against epithelial cells of the intestines (Stenforns Arnesen et al., 2008). In theory, identification of each particular species should be easy. In fact, there are some important problems.

First of them is linked to complex genetic structure of these bacteria. Initial studies using different molecular techniques for the genetic fingerprinting including RAPD (random amplification of polymorphic DNA) or PFGE (pulse-field gel electrophoresis) gave evidences on high level of genetic polymorphism, but they failed in case of establishing species-specific markers (Kaminska et al., 2015). A protein-depended approach called multi-locus enzyme electrophoresis (MLEE) also did not bring new insight into the taxonomy, however all these techniques rather suggested that we deal with one complex species (Helgason et al., 2000). Next, sequencing of $16 \mathrm{~S}$ rRNA revealed $99,1-100 \%$ identity between strains from different taxa (Bartoszewicz et al, 2009), what also suggests one species according to present bacterial species definition. From the other hand, classic and digital DNA-DNA hybridization, a golden standard in taxonomy, often showed less than $70 \%$ similarity (Liu et al., 2015). Values below this cutoff strongly support presence of distinct individual species. Finally, an approach of sequencing several housekeeping genes (technique named MLST, multi-locus sequence typing) proved that phylogenetic structure of $B$. cereus sensu lato corresponds better to their ecological properties than to taxonomic affiliation (Święcicka et al., 2013; Drewnowska and Święcicka 2013; Kamińska et al., 2015). For example, cold adapted bacteria (syn. psychrotolerant) formed independent clade, as well as human pathogens related to B. anthracis. All these recent findings are in fact good arguments for the conception of distinct ecological types (ecotypes), which may be the answer for the problem with clear bacterial taxonomy (Święcicka et al., 2013).

Another problem is linked to horizontal gene transfer (HGT), a quite common process resulting in recombination of genetic information. Naturally, its rate among different microbes varies significantly from low (extremophiles, like cyanobacterium Microcystis spp.) to high values (e.g. Neisseria meningitidis, causative factor for meningitis and sepsis in children). HGT includes three different mechanisms: (a) transformation (obtaining DNA from the environment), (b) transduc- tion (when a bacteriophage is a vector that transmits DNA), and finally (c) conjugation (parasexual process, in which two bacteria of different types join altogether and a donor provides, while recipient receives genetic information). Especially the last one appears to be quite common among $B$. cereus and related bacilli, as showed by Clonal Frame statistical analyzes of homologues recombination to mutation ratio (Vos, Didelot, 2009; Kaminska et al., 2015).

Why conjugation is mentioned as a problem for a concise taxonomic concept of bacteria? First of all, we need to realize that species-characteristic features must be stable and they cannot be transferred to other species or lost during proliferation. In this context, for example, the biosynthesis of Cry proteins which depends on specific, large plasmids containing cry genes is problematic. Numerous extrachromosomal elements with different types of cry genes were already described (Patel et al., 2013). However, if $B$. thuringiensis multiplicates, we cannot exclude the loss of a plasmid, even the plasmid with $c r y$ genes. This would result in the inability to synthesize Cry toxins. In this case, $B$. thuringiensis would
Fig. 2. Horizontal gene transfer among $B$. cereus sensu lato bacteria

Conjugation occurs in different matrices including soil, biofilms or food products. By the transfer of the genes responsible for the presence of species-specific features, bacteria may obtain properties of other taxa becoming indistinguishable from them.

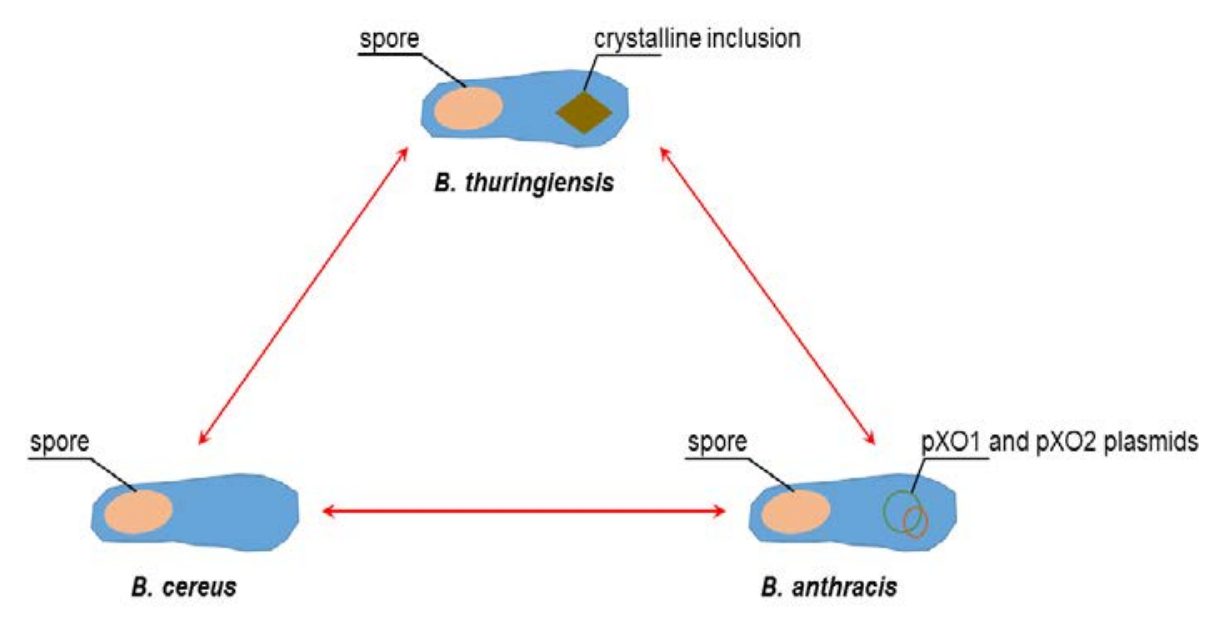


become phenotypically and genotypically indistinguishable from its relative, $B$. cereus (both bacteria show also more than $99 \%$ identity of $16 \mathrm{~S}$ rRNA gene sequence and $>70 \%$ of similarity in DNA-DNA hybridization). Moreover, if $B$. cereus receives $B$. thuringiensis typical plasmid, it will become $B$. thuringiensis-like bacterium. Like above, both important properties of B. anthracis, its toxicity and capsule formation, also require suitable plasmids, in this case pXO1 - for toxins and pXO2 - for capsule (Mock and Fouet, 2001; Cote and Welkos, 2015). Even if their transfer is not common in the natural habitats, several isolates of $B$. cereus provoking symptoms of inhalational anthrax were described. So, the genetic exchange of extrachromosomal elements could cause additional confusion and complications of $B$. cereus sensu lato genetic structure (Modrie et al., 2010). This is illustrated in Fig. 2. It must be mentioned that conjugation is possible between closely related species, however recent studies suggest also HGT events between phylogenetically distant microbes.

\section{Conclusions and ideas for the future}

Apart from serious complications, bacterial taxonomy is not a hopeless case. From the practical point of view, the distinguishing of particular species and elaboration of precise criteria for their identification are of the top interest. Fast and efficient identification of pathogens in medicine and veterinary or food production requires suitable procedures (Bartoszewicz et al., 2008; Obrębska et al., 2008). Complicated taxonomy, different in case of distinct bacteria may lead to the conclusions, that the best solution is an ecological approach. It is based on relationships between microbe and host or environment. For laboratory diagnostics it is not necessary to establish whether bacterium is named B. cereus or B. anthracis, but if it is capable of causing a disease. To assess it, we can perform a PCR test targeted for the pag, cya or lef genes encoding anthrax toxins. Moreover, immunological tests (e.g. enzyme-linked immunosorbent assay called ELISA or immunochromatographic tests) may be used for the detection of protein toxins. This idea, naturally, might be very useful not only regarding B. cereus sensu lato. Staphylococci are divided into coagulase-positive (CPS) and coagulase-negative strains (CNS), both with variable virulence. Next, they are of ten differentiated on the basis their resistance to antibiotics, e.g. MRSA (methicillin-resistant Staphylococcus aureus) or MSSA (methicillin-susceptible S. aureus). This brings clear message for the potential therapy. So in different branches if industry and medicine, test should be focused on interesting properties that might be present among examined bacteria. And what we should do with groups of problematic bacteria, like B. cereus sensu lato? In 2002, Hugenoltz proposed a concept of bacterial groups composed of closely related bacteria with common origin but doubtful taxonomy. According to this suggestion, B. cereus sensu lato should treated as such bacterial group (a rank that has not already been offcially accepted in systematics and taxonomy) because of their common ancestry. However partially limited HGT, ecological isolation and different features favored by natural selection may lead to speciation in the future. Thus a situation observed for B. cereus sensu lato may be a transient state before the formation of valid species.

\section{References}

Bartoszewicz M, Bideshi DK, Kraszewska A, Modzelewska E, Święcicka I (2009). Natural isolates of Bacillus thuringiensis dispay genetic and psychrotrophic properties characteristic of Bacillus weihenstephanensis. J. Appl. Microbiol. 106: 1967-1975.

Bartoszewicz M, Hansen BM, Święcicka I (2008). The members of the Bacillus cereus group are commonly present contaminants of fresh and heat-treated milk. Food Microbiol. 25: 588-596.
Bartoszewicz M, Święcicka I, Buczek J (2006). Cereulidyna i enterotoksyny Bacillus cereus sensu lato. Med. Weter. 62: 28-31.

Cohan FM (2002a). Sexual isolation and speciation in bacteria. Genetica 116: 359-370.

Cohan FM (2002b). What are bacterial species? Annu. Rev. Microbiol. 56: 457-487.

Cohan FM, Perry EB (2007). A systematics for discovering the fundamental units of bacterial diversity. Curr. Biol. 17: 373-386.

Cote CK, Welkos SL (2015). Anthrax toxins in context of Bacillus anthracis spores and spore germination. Toxins 7: 3168-3178.

Drewnowska JM, Święcicka I (2013). Eco-genetic structure of Bacillus cereus sensu lato populations from different environments in northeastern Poland. PLoS One 8: 80175.

Fedyk S, Chetnicki W (2007). Preferential segregation of metacentric chromosomes in simple Robertsonian heterozygotes of Sorex araneus. Heredity 99: 545-552.

Helgason E, Okstad OA, Caugant DA, Johansen HA, Fouet A, Mock M, Hegna I, Kolsto A-B (2000). Bacillus anthracis, Bacillus cereus, and Bacillus thuringiensis - one species on the basis of genetic evidence. Appl. Environ. Microbiol. 66: 2627-2630.

Hugenholtz P (2002). Exploring prokaryotic diversity in the genomic era. Genome Biol. 3(2):REVIEWS0003

Jensen GB, Hansen BM, Eilenberg J, Mahillon J (2003). The hidden lifestyles of Bacillus cereus and relatives. Environ. Microbiol. 5: 631-640.

Kaminska PS, Yernazarowa A, Drewnowska J, Zambrowski G, Święcicka I (2015). The worldwide distribution of genetically and phenotypically diverse Bacillus cereus isolates harbouring Bacillus anthracis-like plasmids. Environ. Microbiol. Rep. 7: 738-745.

Kamińska PS, Fiedoruk K, Jankowska D, Mahillon J, Nowosad K, Drewicka E, Zambrzycka M, Święcicka I (2015). One-day pulsefield gel electrophoresis protocol for rapid determination of emetic Bacillus cereus isolates. Electrophoresis 36: 36: 1051-1054.

Khan AU, Maryam L, Zarrilli R (2017). Structure, genetics and worldwide spread of New Delhi metallo- $\beta$-lactamase (NDM): a threat to public health. BMC Microbiol. 17:101.

Kolsto A-B, Tourasse NJ, Okstad OA (2009). What sets Bacillus an thracis apart from other Bacillus species? Annu. Rev. Microbiol. 63: 451-476.

Liu Y, Lai Q, Goker M, Meier-Kolthoff JP, Wang M, Sun Y, Wang L, Shao Z (2015). Genomic insights into the taxonomic status of the Bacillus cereus group. Sci. Rep. 5: 14082

Maier-Kolthoff JP, Auch AF, Klenk H-P, Goker M (2013). Genome sequence - based species delimitation with confidence intervals distance functions. BMC Bioinformat. 14: 60 .

Małek W, Wdowiak-Wróbel S, Kalita M, Święcicka I, Studzińska B (2005). W poszukiwaniu koncepcji gatunku bakteryjnego. Post. Microbiol. 44: 323-328. 
Maughan H, van der Auwera G (2011). Bacillus taxonomy in the genomic era finds phenotypes to be essential though often misleading. Infect. Genet. Evol. 11: 789-797.

Mayr, E. (1942). Systematics and the Origin of Species (Columbia Univ. Press, New York)

Mayr, E. (1982). The Growth of Biological Thought: Diversity, Evolution, and Inheritance (Belknap Press of Harvard Univ. Press, Cambridge, MA).

Moayeri M, Leppla SH, Vrentas C, Pomerantsev AP, Liu S (2015) Anthrax pathogenesis. Annu. Rev. Microbiol. 69: 185-208.

Mock M, Fouet A (2001). Anthrax. Annu. Rev. Microbiol. 55: 647671.

Modrie P, Beuls E, Mahillon J (2010). Differential transfer dynamics of pAW63 plasmid among members of the Bacillus cereus group in food microcosm. J. Appl. Microbiol. 108: 888-897.

Obrębska K, Szczygła A, Matejczyk M (2008). Skażenia mikrobiologiczne surowców i produktów kosmetycznych. Post. Microbiol. 47: 65-71.

Patel KD, Purani S, Ingle SS (2013). Distribution and diversity analysis of Bacillus thuringiensis cry genes in different soil types and geographical regions of India. J. Invertebr. Pathol. 112: 116-121.

Rasko DA, Altherr MR, Han CS, Ravel J (2005). Genomics of the Bacillus cereus group of organisms. FEMS Microbiol. Rev. 29: 303329.

Ratkiewicz M, Fedyk S, Banaszek A, Gielly L, Chetnicki W, Jadwiszczak K, Taberlet P (2002). The evolutionary history of the two karyotipic races of the common shrew, Sorex araneus in Poland. Heredity 88: 235-242.

Raymond B, Wyres KL, Sheppard LK, Ellis RJ, Bonsall MB (2010). Environmental factors determining the epidemiology and population genetic structure of the Bacillus cereus group in the field. PLoS Pathog. doi.org/10.1371/journal.ppat.1000905

Stenfors Arnesen LP, Fagerlund A, Granum PE (2008). From soil to gut: Bacillus cereus and its food poisoning toxis. FEMS Microbiol. Rev. 32: 579-606.

Święcicka I (2008). Natural occurrence of Bacillus thuringiensis and Bacillus cereus in eukaryotic organisms: a case for symbiosis. Biocontrol Sci. Tech. 18: 221-239.

Święcicka I, Bartoszewicz M, Kasulyte-Creasey D, Drewnowska JM, Murawska E, Yernazarowa A, Lukaszuk E, Mahillon J (2013). Diversity of thermal ecotypes and potential pathotypes of Bacillus thuringiensis soil isolats. FEMS Microbiol. Ecol. 85: 262-272.

Vos M, Didelot X (2009). A comparison of homologous recombination rates in bacteria and archaea. The ISME J 3: 199-208.

Wiedenbeck J, Cohan FM (2011). Origins of bacterial diversity through horizontal genetic transfer and adaptation to new ecological niches. FEMS Microbiol. Rev. 35: 957-976.

\section{Acknowledgments:}

This study was supported by National Science Centre grant (DEC-2011/03/B/ NZ8/02835) to Marek Bartoszewicz. 